\title{
Clinical utility of nuchal translucency screening
}

\author{
This article was published in the following Dove Press journal: \\ Research and Reports in Neonatology \\ 13 October 2014 \\ Number of times this article has been viewed
}

\section{Vedran Stefanovic' \\ Outi Äyräs' \\ Marianne Eronen² \\ Jorma Paavonen' \\ Minna Tikkanen' \\ 'Department of Obstetrics and Gynecology, Helsinki University Central Hospital, ${ }^{2}$ Health Department, \\ The Social Insurance Institution of \\ Finland, Helsinki, Finland}

Correspondence: Vedran Stefanovic Department of Obstetrics and Gynecology, Helsinki University Central Hospital, Haartmaninkatu 2, 00290 Helsinki, Finland

Tel +35840760 558I

Fax +35894717 4801

Email vedran.stefanovic@hus.fi
Abstract: The term nuchal translucency (NT) is used to describe the accumulation of fluid behind the fetal neck visible on ultrasound in the first trimester of pregnancy. In singleton and dichorionic twin pregnancies, increased NT thickness is associated with trisomy 21 and other aneuploidies, major fetal anomalies (especially congenital heart disease), and genetic syndromes. The pathophysiology and significance of increased or discordant NT in monochorionic twin pregnancies is more complex and is associated with twin-to-twin transfusion syndrome and other pregnancy complications due to monochorionicity. The long-term neurological outcome of euploid children without structural anomalies after increased fetal NT seems to be favorable. Proper counseling is essential in the screening process. Special attention should be paid to the assessment of NT screening quality control. Even in the era of arising possibilities for noninvasive fetal karyotype determination from maternal blood, the role of NT screening is far from over. The association of this phenomenon with aneuploidies is only one of its utilities in modern obstetrics.

Keywords: nuchal translucency, screening, aneuploidy, congenital anomaly, counseling, obstetrics

\section{Nuchal translucency - general considerations}

The first report of an increased nuchal thickness (nuchal fold) in fetuses with trisomy 21 during the second trimester was reported almost two decades ago. ${ }^{1}$ This finding is still considered as the most prominent soft marker in the second trimester genetic sonogram. With the advanced ultrasound equipment and demand for an earlier screening for the aneuploidies, the correlate for nuchal fold (nuchal translucency, NT) during the first trimester was reported a few years later. ${ }^{2}$

This novel observation eventually became the basis of a screening procedure that combined ultrasound markers and maternal age. ${ }^{3}$ The ultrasonographic measurement of NT was proposed as a screening method of identifying fetuses at risk for various abnormalities, especially autosomal trisomies, major structural anomalies, or single gene disorders (SGD).

NT is a transient subcutaneous fluid collection at the back of the fetal neck detectable by ultrasound at 10 to 14 weeks of gestation. It is visible in virtually all fetuses at this gestational age which is determined by means of crown-rump length (CRL). ${ }^{2,3}$

NT thickness increases with advancing gestational age. After 14 weeks of gestation it usually vanishes..$^{2-6}$ Normal range of NT measurement changes with gestational age and enlarged NT is variably defined in the literature using a fixed cut off $(2.5,3.0$, or $3.5 \mathrm{~mm})$, a cut off depending on the CRL measurement of the fetus 
(ninety-fifth or ninety-ninth percentile), or by using multiple of median (MoM) approach. ${ }^{7}$

\section{Nuchal translucency measurement technique}

The ideal fetal CRL length for the NT measurement is between 45 and $84 \mathrm{~mm}$ which corresponds to the gestational age from $11^{+0}$ to $13^{+6}$ weeks of pregnancy. ${ }^{6,8}$ The procedure of the NT measurement is the same as that for the measurement of the fetal CRL with an optimal sagittal projection (neutral position). Measurement should not be performed when the fetus is in extreme flexion or hyperextension. The ultrasound calipers are then placed on the skin and soft tissue with the fetus occupying at least $75 \%$ of the screen image. The maximum thickness of the subcutaneous translucency between the skin and soft tissues is measured. Special attention should be given to the distinction between the fetal skin and the amniotic sac line, as both structures appear as thin membranes. ${ }^{9}$ It is generally accepted that at least three separate measurements should be obtained and the mean value of these measurements reported.

The quality of processes and procedures should be continuously assessed since operator variability is a potential problem. ${ }^{10}$ NT measurements must be accurate in order to provide women with reliable screening results. Therefore, systematic training, supervision, and continuing audit are necessary to ensure high-quality screening programs.

\section{Pathophysiology of increased nuchal translucency}

Although many theories have been proposed regarding the pathophysiology of the increased NT, the exact cause of this phenomenon is still unknown. Underdevelopment of the lymphatic system or cardiac anomalies causing early heart failure have been suggested as etiological factors. ${ }^{11-13}$

As an example, in most of the fetuses with Turner syndrome and increased NT, cardiac and lymphatic abnormalities differ significantly from those in other types of aneuploidies and genetic disorders such as Noonan syndrome. Although the trisomy 16 mouse model provides insight into the lymphatic and cardiovascular development (mouse chromosome 16 contains the genetic information found on human chromosomes 21 and 22), the phenotypic expression of cardiac defects seen in this phenotypic variation is not identical to those seen in human trisomy $21 .{ }^{12}$

Other possible etiological factors include altered composition of the extracellular matrix, congenital infections, musculoskeletal anomalies, and hormonal disorders.
Whether a distinction should be made between the NT and cystic hygroma in the first trimester is still questionable and of limited clinical relevance since the management of these situations is identical.

Research on increased NT done on human material is limited to a small number of fetuses with different karyotypes and genetic syndromes. The pathophysiology of the increased NT is probably different depending on the underlying conditions, thus generalization is not possible. Material from affected human pregnancies is difficult to obtain for further investigations since pregnancies involving fetuses with aneuploidy are still terminated in many counties by destructive vacuum aspiration. Even after medical termination of pathological pregnancies, fetal tissues are liquid, fixation very challenging, and consequently pathological examination of such tiny anatomical structures post-mortem is demanding. Additionally, parents with an euploid fetus having increased NT in the first trimester usually decide to continue the pregnancy and in such cases the mystery of increased NT remains unsolved. The etiology of increased NT in monochorionic twin pregnancies is more complex due to the intertwin vascular anastomoses. This is discussed in a separate paragraph.

\section{Increased nuchal translucency and aneuploidy risk}

When used as a single test, screening by NT measurement in the first trimester has a detection rate of approximately $73 \%-82 \%$ for trisomy 21 at a false positive rate of $5 \%-8 \%$. If the NT thickness ranges from 3.5 to $4.4 \mathrm{~mm}$, the risk of a fetal chromosome abnormality is $21 \%$, increasing to $33 \%$ if the NT is from 4.5 to $5.4 \mathrm{~mm}$, and $50 \%$ if the NT is from 5.5 to $6.4 \mathrm{~mm}$. The risk of aneuploidy is $65 \%$ if the NT is $>6.5 \mathrm{~mm}^{.14}$

A large multicenter study in the United Kingdom on trisomy 21 screening in the first trimester of pregnancy was performed by using maternal age and NT thickness. ${ }^{15}$ Almost as many cases of other chromosomal defects than trisomy 21 cases were detected in each group of increased NT.

Also, in the recent large retrospective study the risk of aneuploidy if NT was 3.5 to $4.4 \mathrm{~mm}$ was $25 \%$ and even $76 \%$ if NT was greater than $6.5 \mathrm{~mm} .{ }^{16}$ This study included a large number of fetuses $(n=679)$ with only a minimally increased NT (ninety-fifth percentile $-3.4 \mathrm{~mm}$ ). The main finding was that even minimal increase in NT thickness was associated with adverse pregnancy outcome (17\%). The prevalence of aneuploidies in this group was as high as $10 \%$. This is an important message in counseling, since most fetuses in 
the large cohorts were in the group of minimally increased NT. However, if the karyotype and the second trimester ultrasound scan were normal, there was a 97\% chance of normal outcome, which is in line with the results of other large cohorts. ${ }^{17}$

Although the majority of euploid fetuses with increased NT have a favorable outcome, a minority present with structural or neurodevelopmental abnormalities or syndromes which are visible or detected in the postnatal period. Some of them are a consequence of submicroscopic chromosomal abnormalities that are missed if only conventional karyotyping is performed. ${ }^{18}$ The use and clinical utility of microarray analysis for routine prenatal diagnosis is still being investigated. Important and clinically relevant information may be obtained in certain prenatal situations, such as in fetuses with structural anomalies or those who are stillborn.

Counseling may occasionally be difficult because of the uncertain phenotype associated with some array findings, so called "variant of unknown significance". ${ }^{19}$ Pretest and posttest counseling are imperative whenever prenatal microarray testing is performed. ${ }^{18}$

\section{Increased nuchal translucency and major congenital anomalies}

Increased NT is strongly associated with major congenital anomalies, most of them easily detectable by ultrasound in the second trimester screening. Some of them may be visible also in the first trimester. Although congenital diaphragmatic hernia, clefts, omphalocele, and body stalk anomalies are common in both euploid and aneuploid fetuses with increased NT, structural congenital heart defects (CHD) have been described as the most common anomaly associated with increased NT in large cohorts. ${ }^{16,17,20-22}$ These are associated with high rates of mortality and morbidity, accounting for $20 \%$ of stillbirths and $30 \%$ of neonatal deaths. The prevalence of major cardiac defects increases by increasing degree of NT thickness (between 17/1,000 at NT thickness ninety-fifth percentile $-3.4 \mathrm{~mm}$ and $78 / 1,000$ at NT $\geq 3.5 \mathrm{~mm}) .^{21}$

CHD is a heterogeneous group of conditions; some of them are minor without need for postnatal intervention, while others may lead to serious disability. Due to the improved rate of prenatal diagnosis and the advances in postnatal cardiac surgery, many of the major CHD can be satisfactorily repaired after birth. However, only 5\%-10\% of all major cardiac defects will be detected if a screening strategy is based only on maternal history ie, family history of $\mathrm{CHD}$, maternal diabetes, fetal extracardiac anomaly, and the use of teratogenic drugs (lithium, anti-epileptic drugs). These "at-risk" women account for only $2 \%-5 \%$ of the whole pregnant population.

Previous research on NT and CHD has not focused on defects that would benefit from prenatal detection. In a recent meta-analysis, a subgroup of 159 fetuses with CHD for which prenatal detection would be beneficial were identified antenatally. ${ }^{23}$ The performance of NT as a screening test for detecting these defects was assessed. The NT measurements were compared with NT measurements in 29,776 euploid fetuses without CHD from the Serum Urine and Ultrasound Screening Study (SURUSS) trial. ${ }^{24}$ Using NT cut off of $1.7 \mathrm{MoM}$, the estimated detection rate for a $5 \%$ false positive rate was $52 \%$. Authors concluded, that screening for CHD of fetuses having NT above 1.7 MoM could reasonably identify about half of the cases benefitting from prenatal diagnosis. Continuing pregnancies with NT measurements of 1.7 MoM or greater could be referred for detailed fetal cardiac ultrasound examination. Women found to have affected pregnancies would receive prenatal counseling regarding long-term prognosis of the fetuses with the specific cardiac defect. Affected children, particularly cases where early intervention has been demonstrated to improve prognosis, ${ }^{22}$ could be delivered at units with suitable neonatal expertise. As part of prenatal counseling, termination of pregnancy is often discussed with parents, particularly in cases where CHD is severe.

Although the second trimester sonogram is a valuable tool in prenatal CHD screening, increasing numbers of studies suggest high performance in the late first trimester or even earlier. However, it must be acknowledged that even in experienced hands some CHD remain undetected. An effective strategy for prenatal screening includes an early detection, improved antenatal, intrapartum, and postnatal management reducing morbidity for survivors. $^{25}$

\section{Increased nuchal translucency and single gene disorders}

SGD are caused by individual mutant genes present in one or both chromosomes of a pair. They affect up to $2 \%$ of the population during the entire life span with more than 5,000 described SGD so far. Since the introduction of the NT as screening marker for fetal aneuploidies, the list of genetic syndromes presenting with an increased NT is rapidly growing. The most frequent syndromes frequently associated with increased NT in the first trimester are Noonan syndrome, Smith-Lemli-Opitz syndrome, di George 
syndrome, achondrogenesis, myotonic dystrophy, and some other musculoskeletal disorders.

Most of SGD are relatively rare and are reported in large cohorts of fetuses from unselected populations with increased NT. Recently, the predictive value of increased NT for SDG was assessed in 196 selected pregnancies at risk. ${ }^{26}$ All women were referred because of either maternal or paternal history of Mendelian disorder. The mutation was previously identified in one of the parents in most cases. In a few cases, prenatal diagnosis was carried out because of a risk of germinal mosaicism after de novo mutation in an offspring affected by a dominant single-gene disorder. Monochorionic twin pregnancies were excluded because of the confounding effect on an increased NT of both conditions. Chorionic villus sampling (CVS) was performed in all pregnancies.

The measurement of fetal NT had no association with fetal diagnosis of X-fragile mental retardation syndrome, Huntington disease, and Duchenne muscular dystrophy in these pregnancies as no differences were found between the 63 affected and 116 non-affected fetuses. However, increased NT was associated with two SGD previously undescribed, ie, Hunter syndrome (mucopolysaccharidosis type II) and Emery-Dreifuss dystrophy. Alterations of extracellular matrix could explain this finding in inherited metabolic disorders. Authors concluded that regardless of these associations, it is likely that invasive procedures will remain the standard approach for pregnancies at high risk of SGD.

Another study used multiple technologies (a DNA chip using the APEX technology, quantitative real-time PCR (qPCR), microfluidic PCR, and sequencing) to test 310 mutations across five conditions - Noonan syndrome, congenital adrenal hyperplasia, spinal muscular atrophy (SMA), diGeorge syndrome, and Smith-Lemli-Opitz syndrome in 120 euploid fetuses in order to assess the approach for monitoring SGD associated with the increased NT. ${ }^{27}$ The only significant association was found with Noonan syndrome while the reported association of the remaining four genetic syndromes was weak. As the failure to detect any pregnancies affected by four of the five conditions suggests that the association of these SGD with increased NT is likely to be less than 1 in 100, authors doubt the utility of population screening. Noteworthy, they conclude that the anxiety of patients generated by the knowledge of increased NT can be reduced if the pregnancy is predicted not to be affected with the conditions comprising the current panel.

The largest studies published after the year 2000 of structural anomalies and genetic disorders detected in euploid fetuses with increased NT are displayed in Table 1. ${ }^{16,17,28-31}$

\section{Nuchal translucency screening in twin pregnancies}

Monozygotic pregnancies represent about 33\% of all spontaneously-conceived twins, and two thirds of those are monochorionic. The risk of any pregnancy complication including the most serious such as fetal or neonatal death in monochorionic twin pregnancies is substantially higher than in dichorionic twins. Intertwin vascular anastomoses are present in virtually all monochorionic placentas and may potentially lead to acute or chronic imbalances between the circulations. ${ }^{32}$ In the most severe form, this imbalance may ultimately lead to sudden fetal death or twin-to-twin transfusion syndrome (TTTS) with subsequent high mortality and morbidity.

Monochorionic placentation is the serious pregnancy abnormality which is far more common than fetal malformations. TTTS develops when there is the abnormal

Table I The largest studies published after 2000 reporting outcome of euploid fetuses with increased nuchal translucency in the first trimester screening

\begin{tabular}{|c|c|c|c|c|c|}
\hline Study & $\begin{array}{l}\text { Euploid } \\
\text { fetuses }(n)\end{array}$ & NT (mm) & $\begin{array}{l}\text { Structural } \\
\text { anomalies }\end{array}$ & $\begin{array}{l}\text { Genetic disorders (including } \\
\text { neurodevelopmental delay) }\end{array}$ & $\begin{array}{l}\text { Anomalies detected } \\
\text { after birth }\end{array}$ \\
\hline Mangione et $\mathrm{al}^{28} 200 \mathrm{I}$ & 202 & $\geq 3 \mathrm{~mm}$ & $23 / 202$ (II.4\%) & $\mathrm{I} / 20 \mathrm{I}(0.5 \%)$ & NR \\
\hline Souka et al, ${ }^{29} 200 \mathrm{I}$ & 1,320 & $\geq 3.5 \mathrm{~mm}$ & $162 / 1,320(12.3 \%)$ & $44 / 1,320(3.3 \%)$ & $22 / 980(2.2 \%)$ \\
\hline Michailidis and & 235 & $\geq 95$ th percentile & $5 / 235(2.1 \%)$ & NR & NR \\
\hline \multicolumn{6}{|l|}{ Economides, ${ }^{30} 200 \mathrm{I}$} \\
\hline Senat et al, ${ }^{31} 2002$ & 89 & $\geq 4 \mathrm{~mm}$ & $23 / 89$ (25.8\%) & $4 / 62(6.4 \%)$ & $4 / 62(6.5 \%)$ \\
\hline Bilardo et al, ${ }^{17} 2007$ & 425 & $\geq 95$ th percentile & $27 / 425$ (6.3\%) & $23 / 425$ (5.4\%) & $10 / 375$ (2.7\%) \\
\hline Äyräs et al, ${ }^{16} 2013$ & 834 & $\geq 95$ th percentile & $60 / 834$ (7.2\%) & | 4/834 (I.7\%) & $9 / 834$ (1.1\%) \\
\hline \multirow[t]{2}{*}{ Total } & 3,105 & - & $300 / 2,33 \mid(\mid 2.8 \%)$ & $86 / 2,463(3.4 \%)$ & $45 / 2,25 \mathrm{I}(2.0 \%)$ \\
\hline & & & Range $2.1 \%-25.8 \%$ & Range $0.5 \%-6.4 \%$ & Range $1.1 \%-6.5 \%$ \\
\hline
\end{tabular}

Notes: Adapted from Increased nuchal translucency in euploid fetuses-what should we be telling the parents? Bilardo CM, Timmerman E, Pajkrt M, van Maarle M. Prenatal Diagnosis. 2010;30(2):93-102. Copyright (C) 2010 John Wiley \& Sons, Ltd. ${ }^{32}$

Abbreviations: NR, not reported; NT, nuchal translucency. 
blood transfusion from the donor twin to the recipient twin in cases when the interfetal anastomoses fail to balance the two circulations. The early (first trimester) imbalance in the blood flow through the intertwin vascular anastomoses may result in subtile early cardiac failure of the recipient twin leading to the increased NT. If the imbalance is not self-corrected, the most common result is early fetal death rather than TTTS which occurs later in pregnancy. ${ }^{33,34}$

Sebire et $\mathrm{al}^{35}$ first described increased NT discordance among twins developing TTTS in a retrospective cohort of 303 monochorionic pregnancies. This same observation was confirmed in a larger cohort of 512 monochorionic pregnancies with relatively high predictive value for TTTS. ${ }^{36}$ However, the results of another cohort of 135 monochorionic pregnancies did not support this observation. ${ }^{37}$

The assessment of reversed A wave of ductus venosus (DV) may give better insight and increase predictive value on the development of TTTS in monochorionic twins, especially in cases with discordant NT. This limits the use of NT as an exclusive screening method for identification of those monochorionic pregnancies that are developing TTTS and thus would require closer follow-up and possibly eventual laser treatment. Additionally, assessment of DV flow requires proper ultrasound equipment and high expertise of the operator. ${ }^{38,39}$

The first trimester sonographic screening for aneuploidy provides the opportunity to assess potential prognostic factors in monochorionic twin pregnancies. If a progressively asymmetrical vascular pattern develops, then second trimester features of TTTS will appear.

In monochorionic diamniotic pregnancies the frequency of an abnormal NT is as high as $15 \%$, without epidemiological demonstration of a higher frequency of chromosomal abnormalities compared to singletons and dichorionic twins. Monozygotic twin pairs may have discordant karyotypes (heterokaryotypia) which may result from a mitotic error arising either before twinning, resulting in a mosaic, or after splitting, resulting in the chromosomal abnormality in one of the fetuses. ${ }^{32}$

Unfortunately, there are no data for the distribution of NT in trisomy 21 and fetuses with normal karyotype from monochorionic pregnancies for the purpose of calculating likelihood ratios. ${ }^{32}$ Additionally, in cases of discordant NTs there is no universal agreement which of the two NTs should be considered for risk calculations. However, Cuckle and Maymon have recently described a method for calculating fetus-specific Down syndrome risks from a series of 325 unaffected twins after adjustment for sonographer bias using its own NT value as well as that of the co-twin taking into consideration zygosity, chorionicity, maternal age, ethnical origin, and fetal sex. ${ }^{39}$

In singleton and dichorionic twin pregnancies, enlarged NT (greater than the ninety-fifth percentile) is encountered in about $5 \%$ of cases. In dichorionic twins, patient specific risks for trisomy 21 are calculated for each fetus on the basis of maternal age and the fetal NT and detection rate $(75 \%-80 \%)$ and false positive rate ( $5 \%$ per fetus or $10 \%$ per pregnancy) is similar to those in singleton pregnancies. ${ }^{40,41}$ Therefore, effective screening and diagnosis of major aneuploidies can be achieved in the first trimester, allowing the possibility of earlier and therefore safer selective fetocide and thus improving the pregnancy outcome in cases where one fetus is euploid and the other has either chromosomal abnormality or major structural anomaly. ${ }^{42}$

When screening is done by NT measurement and maternal age, a pregnancy specific risk should be calculated in monochorionic twins. In dichorionic twins, a fetus specific risk should be calculated. ${ }^{43}$

\section{Long-term neurodevelopmental outcome of euploid children from pregnancies with increased nuchal translucency}

Once increased NT is detected, parents need counseling about the expected outcome of the pregnancy. Chromosomal defects can be ruled out by karyotyping. Structural abnormalities are usually diagnosed at the second trimester ultrasound scan. Without major structural anomalies visible on ultrasound, there is a $97 \%-98 \%$ chance of favorable outcome. ${ }^{16,17}$

Neurodevelopmental disorders are impairments of the growth and development of the brain or central nervous system. A narrower use of the term refers to a disorder of brain function that affects emotion, learning ability, selfcontrol, and memory unfolding later during the growth. Neurodevelopmental disorders may manifest as behavioral and cognitive problems. Thus, these disorders occur later in childhood than structural anomalies. A definitive neurodevelopmental diagnosis usually requires long follow-up with repeat examinations. Several studies have been published about the long-term neurodevelopmental outcome of children with increased NT. ${ }^{17,31,44-49}$ The percentage of neurodevelopmental disorders has varied between $1.1 \%$ and $7.4 \%$ in these studies. Comparison of the studies is difficult due to small study populations and variable NT cutoff levels and methods. 
According to the most recent publications, the neurological outcome of children after increased fetal NT seems to be favorable by the age of 24 months. ${ }^{48,49}$

\section{Management of pregnancies with increased nuchal translucency}

After detailed anatomy survey, CVS or amniocentesis should be offered to all women for karyotyping. Some authors have proposed that, in fetuses with enlarged NT and obvious structural major anomalies, termination of pregnancy may be offered directly to save the cost of karyotyping. This approach is not acceptable (unless parents are reluctant to undergo karyotyping after counseling) in contemporary perinatal practice for several reasons: 1) pregnant women should be offered all necessary investigations to clarify the etiology of the increased NT; 2) karyotyping is important not only to define the recurrence of risk, but also to help parents in the decision making process; 3 ) postmortem karyotyping is not always possible and even in experienced laboratories, culture failure may be as high as $15 \%$.
In fetuses with grossly enlarged NT, cystic hygroma or hydrops, ultrasound should be performed again at 15 weeks to ensure fetal viability. In euploid fetuses with continuation of pregnancies, third level detailed ultrasound assessment of fetal anatomy with special attention to fetal echocardiography should be offered around 20 weeks. In cases of any major structural anomaly, a multidisciplinary team should be involved in counseling, pregnancy follow-up, timing and organizing delivery in the third-level prenatal center with high quality neonatal care. Intrauterine treatment should be offered, if possible.

In the case of intrauterine demise, fetal autopsy and other investigations to reveal etiology of increased NT should be a standard care followed by proper counseling. Psychological support to the family should not be ignored.

There is no general consensus on how to proceed after birth in pregnancies with euploid fetuses without obvious structural anomalies. The minimum requirement is clinical examination of the neonate. Since it is generally accepted that long-term neurological outcome is favorable in such cases, there is no need for special follow-up.

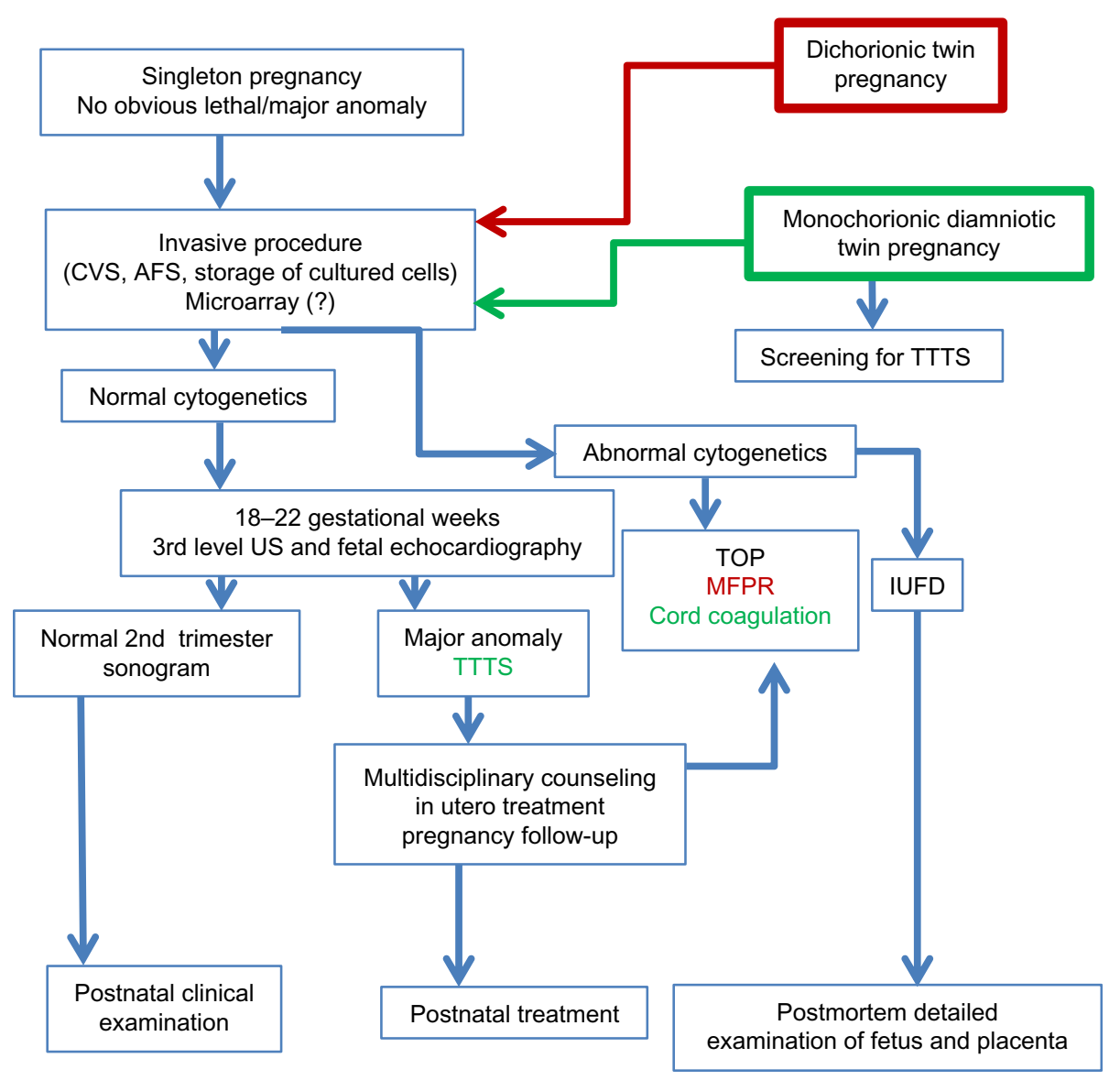

Figure I A protocol of management of pregnancies with increased fetal nuchal translucency on singleton, monochorionic and dichorionic twin pregnancies. Abbreviations: CVS, chorionic villus sampling; AFS, amniotic fluid sampling; TTTS, twin-to-twin transfusion syndrome; TOP, termination of pregnancy; MFPR, multifetal pregnancy reduction; IUFD, intrauterine fetal death; US, ultrasound. 
A protocol of management of pregnancies with increased fetal NT on singleton, monochorionic, and dichorionic twin pregnancies is shown in Figure 1.

\section{Antenatal counseling and patients' awareness}

Apart from the tremendous possibilities highly valued by pregnant women, prenatal screening carries also limitations, ethical issues, and potentially difficult decisions. There is generally accepted consensus that participation in the prenatal screening should be based on informed consent. ${ }^{50}$ Providing professional and comprehensive information on prenatal examinations is challenging and often remains inadequate. Unfortunately, prenatal screening decisions are often not informed decisions. This is inconsistent with the main objective of offering screening which is to enable individuals to make informed decisions..$^{51}$ Ethical issues, educational level, and language barriers should also be taken into consideration. ${ }^{52}$

Regarding NT screening, there should be three levels of counseling: 1) pre-screening (informed decision about the screening based on the health provider's information about the benefits and possible harms of screening regarding false-positive results); 2) counseling after increased NT detection (invasive procedures and related risk, "residual" risk of major structural anomaly in euploid fetuses); 3) counseling after detection of aneuploidy or major structural anomaly since the outcome greatly varies among various aneuploidies and structural anomalies. A multidisciplinary expert team should be involved in such cases with additional individual psychological support to the parents.

\section{Conclusion}

NT screening is the powerful tool in modern obstetrical practice which enables increased detection of aneuploidies and major structural anomalies and ultimately leads to better quality of obstetric care. Significance of NT screening for detection of SGS and prediction of TTTS in monochorionic twin pregnancies is still disputable. The long-term neurological outcome of euploid children without structural anomalies after increased fetal NT seems to be favorable. Quality of NT screening should be high. Counseling should be improved due to the high level of anxiety and emotional impact linked to NT screening.

\section{Disclosure}

The authors have no conflicts of interest to report.

\section{References}

1. Benacerraf BR, Frigoletto FD Jr, Laboda LA. Sonographic diagnosis of Down syndrome in the second trimester. Am J Obstet Gynecol. 1985;153(1):49-52.

2. Szabó J, Gellén J. Nuchal fluid accumulation in trisomy-21 detected by vaginosonography in first trimester. Lancet. 1990;336(8723):1133.

3. Nicolaides KH, Azar G, Byrne D, Mansur C, Marks K. Fetal nuchal translucency: ultrasound screening for chromosomal defects in first trimester of pregnancy. BMJ. 1992;304(6831):867-869.

4. Nicolaides KH, Brizot ML, Snijders RJ. Fetal nuchal translucency: ultrasound screening for fetal trisomy in the first trimester of pregnancy. Br J Obstet Gynaecol. 1994;101(9):782-786.

5. Pajkrt E, Bilardo CM, van Lith, Mol BW, Bleker OP. Nuchal translucency measurement in normal fetuses. Obstet Gynecol. 1995;86(6): 994-997.

6. Nicolaides KH, Heath V, Cicero S. Increased fetal nuchal translucency at 11-14 weeks. Prenat Diagn. 2002;22(4):308-315.

7. Maymon R, Tercanli S, Dreazen E, Sartorius G, Holzgreve W, Herman A. Comparison of pregnancy outcome of euploid fetuses with increased nuchal translucency (NT) expressed in NT MoM or delta-NT. Ultrasound Obstet Gynecol. 2004;23(5):477-481.

8. Hafner E, Schuchter K, Philipp K. Screening for chromosomal abnormalities in an unselected population by fetal nuchal translucency. Ultrasound Obstet Gynecol. 1995;6(5):330-333.

9. Wald NJ, Kennard A, Hackshaw A, McGuire A. Antenatal screening for Down's syndrome. Health Technol Assess. 1998;2(1):i-iv, 111-112.

10. Blakemore KJ. Nuchal translucency. Ultrasound Obstet Gynecol. 1998;11(6):388-390.

11. Haak MC, van Vugt JMG. Pathophysiology of increased nuchal translucency: a review of the literature. Hum Reprod Update. 2003;9(2): 175-184.

12. Bekker MN, Arkesteijn JB, van den Akker HM, et al. Increased NCAM expression and vascular development in trisomy 16 mouse embryos: relationship with nuchal translucency. Pediatr Res. 2005;58(6): $1222-1227$.

13. Nafziger E, Vilensky JA. The anatomy of nuchal translucency at 10-14 weeks gestation in fetuses with Trisomy 21: An incredible medical mystery. Clin Anat. 2014;27:353-359.

14. Nicolaides KH. Nuchal translucency and other first-trimester sonographic markers of chromosomal abnormalities. Am J Obstet Gynecol. 2004;191(1):45-67.

15. Snijders RJ, Noble P, Sebire N, Souka A, Nicolaides KH. UK multicentre project on assessment of risk of trisomy 21 by maternal age and fetal nuchal-translucency thickness at 10-14 weeks of gestation. Fetal Medicine Foundation First Trimester Screening Group. Lancet. 1998;352(9125):343-346.

16. Äyräs, O, Tikkanen M, Eronen M, Paavonen J, Stefanovic V. Increased nuchal translucency and pregnancy outcome: a retrospective study of 1063 consecutive singleton pregnancies in a single referral institution. Prenat Diagn. 2013;33:856-862.

17. Bilardo CM, Müller MA, Pajkrt E, Clur SA, van Zalen MM, Bijlsma EK. Increased nuchal translucency thickness and normal karyotype: time for parental reassurance. Ultrasound Obstet Gynecol. 2007;30(1):11-18

18. Savage MS, Mourad MJ, Wapner RJ. Evolving applications of microarray analysis in prenatal diagnosis. Curr Opin Obstet Gynecol. 2011;23(2):103-108.

19. Reiff M, Bernhardt BA, Mulchandani S, et al. "What does it mean?": Uncertainties in understanding results of chromosomal microarray testing. Genet Med. 2012;14(2):250-258.

20. Chew C, Halliday JL, Riley MM, Penny DJ. Population-based study of antenatal detection of congenital heart disease by ultrasound examination. Ultrasound Obstet Gynecol. 2007;29(6):619-624.

21. Hyett J, Perdu M, Sharland G, Snijders R, Nicolaides KH. Using fetal nuchal translucency to screen for major congenital cardiac defects at 10-14 weeks of gestation: population based cohort study. BMJ. 1999;318(7176):81-85. 
22. Wald NJ, Kennard A. Routine ultrasound scanning for congenital abnormalities. Ann N Y Acad Sci. 1998;847:173-180.

23. Wald NJ, Morris JK, Walker K, Simpson JM. Prenatal screening for serious congenital heart defects using nuchal translucency: a meta-analysis. Prenat Diagn. 2008;28(12):1094-1104.

24. Wald NJ, Rodeck C, Hackshaw AK, Walters J, Chitty L, Mackinson AM. First and second trimester antenatal screening for Down's syndrome: the results of the Serum, Urine and Ultrasound Screening Study (SURUSS). J Med Screen. 2003;10:56-104.

25. Khoshnood B, De Vigan C, Vodovar V, et al. Trends in prenatal diagnosis, pregnancy termination, and perinatal mortality of newborns with congenital heart disease in France, 1983-2000: a population-based evaluation. Pediatrics. 2005;115(1):95-101.

26. Arigita M, Borrell A, Mula R, Sanchez A, Milà M, Gratacos E. Use of fetal nuchal translucency in the first trimester to predict single-gene disorders. Prenat Diagn. 2011;31(12):1164-1168.

27. Pergament E, Alamillo C, Sak K, Fiddler M. Genetic assessment following increased nuchal translucency and normal karyotype. Prenat Diagn. 2011;31(3):307-310.

28. Mangione R, Guyon F, Taine L, et al. Pregnancy outcome and prognosis in fetuses with increased first-trimester nuchal translucency. Fetal Diagn Ther. 2001;16(6):360-363.

29. Souka AP, Krampl E, Bakalis S, Heath V, Nicolaides KH. Outcome of pregnancy in chromosomally normal fetuses with increased nuchal translucency in the first trimester. Ultrasound Obstet Gynecol. 2001;18(1):9-17.

30. Michailidis GD, Economides DL. Nuchal translucency measurement and pregnancy outcome in karyotypically normal fetuses. Ultrasound Obstet Gynecol. 2001;17(2):102-105.

31. Senat MV, De KB, Audibert F, Montcharmont G, Frydman R, Ville Y. Pregnancy outcome in fetuses with increased nuchal translucency and normal karyotype. Prenat Diagn. 2002;22(5):345-349.

32. Bilardo CM, Timmerman E, Pajkrt E, van Maarle M. Increased nuchal translucency in euploid fetuses - what should we be telling the parents? Prenat Diagn. 2010;30:93-102.

33. Taylor MJ, Denbow ML, Tanawattanacharoen S, Gannon C, Cox PM, Fisk NM. Doppler detection of arterio-arterial anastomoses in monochorionic twins: feasibility and clinical application. Hum Reprod. 2000:15(7):1632-1636.

34. Zoppi MA. Nuchal translucency screening in monochorionic twin pregnancies. Ultrasound Obstet Gynecol. 2009;34(5):491-493.

35. Sebire NJ, Souka A, Skentou H, Geerts L, Nicolaides KH. Early prediction of severe twin-to-twin transfusion syndrome. Hum Reprod. 2000;15(9):2008-2010.

36. Kagan K, Gazzoni A, Sepulveda-Gonzalez, Sotiriadis A, Nicolaides, KH. Discordance in nuchal translucency thickness in the prediction of severe twin-to-twin transfusion syndrome. Ultrasound Obstet Gynecol. 2007;29(5):527-532.

37. Fratelli N, Prefumo F, Fichera A, Valcamonico A, Marella D, Frusca T. Nuchal translucency thickness and crown rump length discordance for the prediction of outcome in monochorionic diamniotic pregnancies. Early Hum Dev. 2011;87(1):27-30.

38. Antsaklis A, Pergialiotis V, Theodora M, Papazefkos V, Antsaklis P. Early prediction of Twin-to-Twin Transfusion Syndrome with the use of First Trimester Ultrasound Markers: Is it Possible? Donald School J Ultrasound Obstet Gynecol. 2013;781:66-72.
39. Cuckle H, Maymon R. Down syndrome risk calculation for a twin fetus taking account of the nuchal translucency in the co-twin. Prenat Diagn. 2010;30:827-833.

40. Matias A, Montenegro N, Loureiro T, et al. Screening for twin-twin transfusion syndrome at 11-14 weeks of pregnancy: The key role of ductus venosus blood flow assessment. Ultrasound Obstet Gynecol. 2010;35(2):142-148.

41. Sebire NJ, Snijders RJ, Hughes K, Sepulveda W, Nicolaides KH. Screening for trisomy 21 in twin pregnancies by maternal age and fetal nuchal translucency thickness at 10-14 weeks of gestation. Br J Obstet Gynaecol. 1996;103(10):999-1003.

42. Audibert F, Gagnon A, Genetics Committee of the Society of Obstetricians and Gynaecologists of Canada; Prenatal Diagnosis Committee of the Canadian College of Medical Geneticists. Prenatal screening for and diagnosis of aneuploidy in twin pregnancies. J Obstet Gynaecol Can. 2011;33(7):754-767.

43. Nobili E, Paramasivam G, Kumar S. Outcome following selective fetal reduction in monochorionic and dichorionic twin pregnancies discordant for structural, chromosomal and genetic disorders. Aust N Z J Obstet Gynaecol. 2013;53(2):114-118.

44. Brady AF, Pandya PP, Yuksel B, Greenough A, Patton MA, Nicolaides KH. Outcome of chromosomally normal livebirths with increased fetal nuchal translucency at 10-14 weeks' gestation. J Med Genet. 1998;35(3):222-224.

45. Hiippala A, Eronen M, Taipale P, Salonen R, Hiilesmaa V. Fetal nuchal translucency and normal chromosomes: a long-term follow-up study. Ultrasound Obstet Gynecol. 2001;18(1):18-22.

46. Senat MV, Bussieres L, Couderc S, et al. Long-term outcome of children born after a first-trimester measurement of nuchal translucency at the 99th percentile or greater with normal karyotype: a prospective study. Am J Obstet Gynecol. 2007;196(1):53. e1-e6.

47. Schou KV, Kirchhoff M, Nygaard U, Jorgensen C, Sundberg K. Increased nuchal translucency with normal karyotype: a follow-up study of 100 cases supplemented with CGH and MLPA analyses. Ultrasound Obstet Gynecol. 2009;34(6):618-622.

48. Mula R, Gonce A, Bennasar M, et al. Increased nuchal translucency and normal karyotype: perinatal and pediatric outcomes at 2 years of age. Ultrasound Obstet Gynecol. 2012;39(1):34-41.

49. Miltoft CB, Ekelund CK, Hansen BM, et al. Increased nuchal translucency, normal karyotype and infant development. Ultrasound Obstet Gynecol. 2012;39(1):28-33.

50. Raffle AE. Information about screening - is it to achieve high uptake or to ensure informed choice? Health Expect. 2001;4(2): 92-98.

51. van den Berg M, Timmermans DR, ten Kate LP, van Vugt JM, van der Wal G. Informed decision making in the context of prenatal screening. Patient Educ Couns. 2006;63(1-2):110-117.

52. Dahl K, Hvidman L, Jørgensen FS, Kesmodel US. Knowledge of prenatal screening and psychological management of test decisions. Ultrasound Obstet Gynecol. 2011;38(2):152-157.
Research and Reports in Neonatology

\section{Publish your work in this journal}

Research and Reports in Neonatology is an international, peer-reviewed, open access journal publishing original research, reports, editorials, reviews and commentaries on neonatal health. The manuscript management system is completely online and includes a very quick and fair

\section{Dovepress}

peer-review system. Visit http://www.dovepress.com/testimonials.php to read real quotes from published authors. 